$\xi$

\title{
Critical Care Nurses' Knowledge, Attitudes, and Perceived Barriers towards Pressure Injuries Prevention
}

\author{
Abdul-Monim Batiha ${ }^{1}$ \\ ${ }^{1}$ Faculty of Nursing, Philadelphia University, Amman, Jordan \\ E-mail: abatiha@philadelphia.edu.jo \\ abatiha@gmail.com
}

\begin{abstract}
Background: Pressure injuries are a considerable problem for hospitalized critically ill and elderly patients, as such injuries produce pain, and reduce total wellbeing, resulting in increased morbidity and mortality, as well as often extending those patients' hospital stays Purpose: The purpose of this study was to determine critical care nurses knowledge, attitudes, and perceived barriers toward pressure injuries prevention.

Design: A descriptive cross-sectional survey was performed, using a questionnaire method to critical care nurses'. The study took place between August and October 2017 and involved ten hospitals: two university hospital, six public hospitals, and two private hospitals.

Methods: Data were collected by means of a questionnaire using two valid and reliable instruments: i) the Pressure Ulcer Knowledge Assessment Tool 2.0, and ii) Attitude Toward Pressure Ulcer Prevention and two newly developed instruments sociodemographic and perceived barriers toward pressure injury prevention.

Results: The entire mean knowledge score for the participants was $54.9 \%$, and overall high attitude scores were $76.7 \%$. Level of education, years employed in a critical care unit, training received on pressure injury prevention, and the number of papers read on pressure injury prevention was all identified as having a significant and independent effect on participants' knowledge concerning prevention of pressure injuries. To evaluate the effect of demographic characteristics on nurses' attitudes, the only significant variable was "years of employment in critical care units". Shortage of staff was the most commonly cited barrier faced by critical care nurses' during practice.
\end{abstract}

Keywords: Attitudes, Barriers, Critical care nurses', Jordan, Knowledge, Pressure injuries

\section{Introduction}

Pressure injuries (PI) may be defined as "ischemic soft tissue injuries resulting from pressure, usually over bony prominences (e.g., sacrum, calcaneus, and ischium)" (Yamada, Inoue, Shimokawa\& Sakata, 2017). Pressure injuries (PI) can also be a consequence of badly fitting appliances or casts. Soft tissues are more vulnerable to injury than the skin; consequently, the external appearance of PI may undervalue the extent of the injury (Yamada et al., 2017).

Even with the use of evidence-based practice to prevent them, PI occur in critically ill patients; the incident rates range between $14 \%$ to $51 \%$ of all hospitalized patients (Serpa, Santos, Oliveira, Caetano, \& Donadon, 2011).In Jordan, a rate of $12 \%$ has been reported (Tubaishat, Anthony, \& Saleh, 2011; Batiha, 2014; Bashayreh et. Al. 2015).

The treatment of PI case starts with a complete evaluation of the general medical condition of the patient and his/her wound. Injuries should be evaluated for size, stage, sinus tracts, necrotic tissue, exudation, as well as the existence of granulation (Qaseem, Humphrey, Forciea, Starkey, \& Denberg, 2015).

Preventive actions done by a critical care nurse $(\mathrm{CCN})$, with an emphasis on positioning and support to reduce conditions contributing to the pressure ulcer or injuries, must be given to all patients, especially those already with PI. Any ulcer progression should emphasize the need to evaluate and accentuate preventive actions that are already available (Ozyurek \&Yavuz, 2015). Patients with PI generally have more additional diseases; PI is, at best, only a weak predictor of death (Schlüer, 2017).

Critical care nurses (CCNs), as frontline caregivers, bear much of the responsibility for the implementation of strategies to prevent PI. Understanding CCNs' knowledge, attitudes and perceived barriers toward PI prevention are paramount to the successful intervention of a PI prevention program, and to the understanding of clinical situations in which strategies to prevent PI may be ineffective or even futile (Serpa et al., 2011).

Knowledge deficit can often be a significant cause leading to the development of PI; thus, CCNs need ongoing education and training about PI prevention (Galvão, Serique, Santos, \& Nogueira, 2017). Furthermore, improved PI prevention knowledge between CCNs not merely enhances the high quality of care provided to patients but also decreases the number of critical patients suffering from PI, as well as the duration of their hospital stays (Serpa et al., 2011).

To enhance the high quality of their caring, nurses should have upto-date knowledge and practice regarding the prevention of PI. Knowledge is essential to identify a) patients who are at high risk of developing PI, b) which measures are effective in the treatment of PI and c) how to apply these measures. Knowledge has a direct impact on a nurse's attitudes towards PI; a mindset which is significantly associated with the application of acceptable PI prevention techniques (Cox \& Schallorm, 2017; Obead, 2014). Negative 
attitudes towards PI prevention, together with a deficiency of knowledge, are considered as one of the most widespread barriers to the use of preventive strategies in a clinical setting (Beeckman, Defloor, Schoonhoven, \&Vanderwee, 2011).

In Jordan, there is a lack of data pertaining to PI prevention in healthcare settings. No in-country study has addressed CCNs' knowledge, attitudes, and perceived barriers toward the prevention of pressure injuries.

\subsection{Aim}

The aim of this study was to determine CCNs' knowledge, attitudes, and perceived barriers toward PI prevention.

\section{Methods}

\subsection{Participants and sampling procedure}

The sample size was estimated based on single population formula with the assumption of: margin of error $5 \%$, sample proportion $50 \%$, confidence level $95 \%$ and. Population (critical care nurses) was less than 900; correction formula was used, the recommended sample size is 270 . Utilizing convenience sampling, we tried to gain access to almost most of CCNs in Jordanian hospitals; 270 participants were accessed from ten hospitals. The inclusion criteria were a) CCNs who have direct contact with the PI patients b) have at least one year experience, and exclude only those who were not fit to inclusion criteria or refused to participate.

\subsection{Setting and design}

A descriptive cross-sectional survey design was used. It employed a questionnaire for data gathering from the CCNs' in ten Jordanian hospitals: two university hospital, six public hospitals, and two private hospitals.

\subsection{Data collection}

In each of the ten hospitals in this study, research assistants were accountable for: a) the selection of nurse respondents, b) distributing the questionnaires, c) obtaining the signed consent forms and d) handing out the participant information sheets to those who willingly agreed to participate in the research. The study took place between August and October 2017.

Completed approval forms were gathered independently to assure anonymity and confidentiality.

\subsection{Ethical considerations}

Ethical approval was provided by Philadelphia University of Jordan, and from each hospital included in the study. All involvement in the study was voluntary. The privacy of the research participants, together with the participating hospitals, was guaranteed.

\subsection{Data collection instruments}

Four instruments were used to gather the information for this study:

1. Sociodemographics including age, gender, qualifications, years employed in a critical care unit, received training on PI prevention, and read papers on PI prevention.

2. "Pressure Ulcer Knowledge Assessment Tool (PUKAT) 2.0 is an updated and revised edition of the Pressure Ulcer Knowledge Assessment Tool (PUKAT) created by Beeckman et al. (2010). The modified edition was created using state-of-the-art approaches to build evidence about reliability and validity. The instrument comprises of 25 multiple-choice questions, within six themes, to cover all aspects of PI prevention. Different kinds of validity were evaluated: the extent of difficulty was reasonable ( $P$ - value) average 0.56 , the content validity, reliability, and internal consistency was good. The stability of the tool was measured using the intraclass correlation coefficient $(I C C)=0.69$ " (Manderlier et al., 2017).

3. "Attitude toward Pressure Ulcer Prevention (APuP)": this tool includes 5 factors and 13 items to assess attitudes toward PI prevention. This tool was analyzed for internal consistency $(0.79)$ and content validity. Total scores were measured to acquire the complete attitude scores. Scores on the negatively written items were reversed to obtain a complete score. The scoring values for this instrument range from 13 (minimal score) value) to 52 (maximum score) (MS) value. The instrument obtained an acceptable total internal consistency, via Cronbach's alpha of 0.79 , and stability testing (ICC of 0.88 was found) (Beeckman et al., 2010a).

4. Perceived Barriers Toward PI Prevention: this instrument was developed by the researcher for the purpose of this study, and composed of 19 possible barriers faced by CCNs during clinical practice that prevent or reduce good care practice, as revealed in the literature (Dilie and Mengistu, 2015; Tubaishat et al., 2013; Strand and Lindgren, 2010).

\subsection{Data analysis}

Collected data were coded and put into SPSS Statistics (v17). Inferential and descriptive statistical procedures were conducted. Percentages and frequencies for every item within the knowledge, attitude and barrier categories were measured. The mean score attained from the scale was used to measure subjects' attitudes. Correlation analysis was used to identify the effect of participant knowledge concerning prevention of PI. Final results for $p<0.05$ were regarded significant.

\section{Results}

\subsection{Demographics}

The questionnaire was sent to $350 \mathrm{CCNs}$ employed in ten Jordanian hospitals. 80 forms came back that were either incomplete or empty; therefore, 270 questionnaires were returned that were usable, a response rate of $77 \%$.

Participants' demographics are provided in Table 1.

Table. 1. Demographic characteristics

\begin{tabular}{|c|c|}
\hline Variables & No. $(\%)$ \\
\hline Sex & $270(100)$ \\
\hline Female & $162(60)$ \\
\hline Male & $108(40)$ \\
\hline \multicolumn{2}{|l|}{ Age } \\
\hline 20-29 years & $170(62.7)$ \\
\hline 30-39 years & $72(26.7)$ \\
\hline$\geq 40$ years & $28(10.4)$ \\
\hline \multicolumn{2}{|l|}{ Level of education } \\
\hline Diploma & $37(13.7)$ \\
\hline Bachelor's degree & $212(78.5)$ \\
\hline Master's degree & $21(7.8)$ \\
\hline Doctorate & 0 \\
\hline \multicolumn{2}{|c|}{ Years employed in the critical care unit } \\
\hline $0-5$ & $129(47.8)$ \\
\hline $6-10$ & $114(42.2)$ \\
\hline$>11$ & $27(10)$ \\
\hline \multicolumn{2}{|c|}{ Received training on PU prevention } \\
\hline Course or lecture & $102(37.8)$ \\
\hline Conference or workshop & $29(10.7)$ \\
\hline Never received training & $139(51.5)$ \\
\hline \multicolumn{2}{|l|}{ Read papers on PU prevention } \\
\hline$<1$ month ago & $6(2.2)$ \\
\hline $1-12$ months ago & $30(11.1)$ \\
\hline$>1$ year & $81(30)$ \\
\hline Never & $153(56.7)$ \\
\hline
\end{tabular}

The higher percentages of the participants were female nurses $(60 \% ; n=162)$ and the greater part $(62.7 \% ; n=170)$ were in the age 
group: 20-29 years. Most participants possessed bachelors (78.5\%, $\mathrm{n}=212)$ or diploma degrees $(13.7 \% ; \mathrm{n}=73) ; 47.8 \%(\mathrm{n}=129)$ had $0-5$ years' experience in CCUs.

More than half of the participants $(51.5 \% ; n=139)$ had not obtained any formal education or training on PI prevention since they had begun working as critical care nurses.

More than half of the participants $(56.7 \% ; n=153)$ had never read any research articles on PI prevention; whereas $43.3 \%(n=117)$ had A small number of nurses had read a paper on PI prevention within the last 12 months $(11.1 \%$; $=30)$.

\subsection{Knowledge}

The overall mean knowledge score was $54.9 \%$ (13.7out of a possible 25). The participants' scores ranged from 1 to 22 , with no CCNs achieving $100 \%$. From the participants, only $25 \%$ of the nurses achieved a mean score of $\geq 63 \%$. The minimum entire scores were obtained on theme 5: Prevention of PI (45.5\%) and theme (6): Specific patient groups (49\%)

Maximum scores (MS) were obtained on a theme (4): Nutrition (63.9\%), theme (3): Risk assessment $(63.1 \%)$, and theme (1): etiology $(56.2 \%)$. (See Table 2).

Table. 2. Critical care Nurses Knowledge regarding prevention of pressure

\begin{tabular}{ll} 
ulcer. & Overall \% of correct answers \\
\hline Items & $56.2 \%$ \\
\hline Theme 1: Etiology & $51.6 \%$ \\
Theme 2: Classification and observation & $63.1 \%$ \\
Theme 3: Risk assessment & $63.9 \%$ \\
Theme 4: Nutrition & $45.5 \%$ \\
Theme 5: Prevention of pressure ulcers & $49.2 \%$ \\
Theme 6: Specific patient groups & $54.9 \%$ \\
Total
\end{tabular}

Using correlation analysis, the issues identified as having a significant (p-value of $<0.05$ ) and independent effect on participants' knowledge concerning the prevention of PI were: i) the nurse's level of education, ii) number of years employed in critical care units ranging from $0-5$ years, compared to more than 11years, iii) receiving training on PI prevention and iv) reading papers on PI prevention.

The results of this study revealed no significant difference in the knowledge mean scores between male and female respondents $(p=0.378)$, age group $\left(\chi^{2}\right.$ test, $\left.p=0.214\right)$.

\subsection{Attitudes}

Table 3 reveals CCNs' attitudes regarding the prevention of PI. The overall attitude scores for the participants were: mean $=39.9$, $\mathrm{SD}=3.8,76.7 \%$. The APuP composed of 5 factors (themes) and 13 items. The maximum mean score for items in the theme (3): "A PI almost never causes discomfort for a patient" (mean $=3.9, \mathrm{SD}=0.6$, $97.5 \%$ ). The minimum mean score for items in the theme (1): "PI prevention is too difficult. Others are better than I am" (mean=2.1, $\mathrm{SD}=0.8,52.5 \%$ ).

In the first theme: Personal competency to prevent PI (mean=7.2, $\mathrm{SD}=1.2,60 \%$ ). The maximum mean score in this theme: "I am well trained to prevent PI (mean=2.6, SD=0.9, 65\%). In the second theme: Priority of pressure injury prevention" (mean=9.3, $\mathrm{SD}=1.4,77.5 \%$ ), the maximum mean score: "Pressure injury prevention should be a priority" (mean $=3.5, \mathrm{SD}=0.7,87.5 \%$ ), and the minimum mean score: Too much attention goes to the prevention of pressure injuries (mean $=2.7, \mathrm{SD}=0.8,67.5 \%$ ). In the third theme: Impact of PI: (mean=10.4, SD=1.5, 86.6\%), the minimum mean score in this theme: "The financial impact of PI on a patient should not be exaggerated": (mean $=3.1, \mathrm{SD}=0.8,77.5$ ).
Table. 3. Critical care nurses attitude regarding prevention of pressure ulcer. (MS= 52).

\begin{tabular}{|c|c|c|c|c|}
\hline Attitude towards APuP & $\begin{array}{l}\text { Mean } \\
\text { scores }\end{array}$ & $\begin{array}{c}\text { Mean } \\
\%\end{array}$ & $M S$ & $S D$ \\
\hline $\begin{array}{l}\text { F1. Personal competency to prevent } \\
\text { pressure ulcers }\end{array}$ & 7.2 & 60 & 12 & 1.2 \\
\hline $\begin{array}{l}+\quad \text { I feel confident in my ability to } \\
\text { prevent pressure ulcers. }\end{array}$ & 2.5 & 62.5 & 4 & 1.1 \\
\hline $\begin{array}{l}+\quad \text { I am well trained to prevent pres- } \\
\text { sure ulcers. }\end{array}$ & 2.6 & 65 & 4 & 0.9 \\
\hline $\begin{array}{l}\text { Pressure ulcer prevention is too } \\
\text { difficult. Others are better than I } \\
\text { am. }\end{array}$ & 2.1 & 52.5 & 4 & 0.8 \\
\hline $\begin{array}{l}\text { F2. Priority of pressure ulcer preven- } \\
\text { tion }\end{array}$ & 9.3 & 77.5 & 12 & 1.4 \\
\hline $\begin{array}{l}\text { - Too much attention goes to the } \\
\text { prevention of pressure ulcers. }\end{array}$ & 2.7 & 67.5 & 4 & 0.8 \\
\hline $\begin{array}{l}\text { - Pressure ulcer prevention is not } \\
\text { that important. }\end{array}$ & 3.1 & 77.5 & 4 & 1.3 \\
\hline $\begin{array}{l}+\quad \text { Pressure ulcer prevention should } \\
\text { be apriority. }\end{array}$ & 3.5 & 87.5 & 4 & 0.7 \\
\hline F3. Impact of pressure ulcers & 10.4 & 86.6 & 12 & 1.5 \\
\hline $\begin{array}{l}\text { A pressure ulcer almost never } \\
\text { causes discomfort for a patient. }\end{array}$ & 3.9 & 97.5 & 4 & 0.6 \\
\hline $\begin{array}{l}\text { The financial impact of pressure } \\
\text { ulcers on a patient should not be } \\
\text { exaggerated. }\end{array}$ & 3.1 & 77.5 & 4 & 0.8 \\
\hline $\begin{array}{l}+\quad \text { The financial impact of pressure } \\
\text { ulcers on society is high. }\end{array}$ & 3.4 & 85 & 4 & 1.2 \\
\hline $\begin{array}{l}\text { F4. Responsibility in pressure ulcer } \\
\text { prevention }\end{array}$ & 6.1 & 76.3 & 8 & 0.9 \\
\hline $\begin{array}{l}\text { I am not responsible if a pressure } \\
\text { ulcer develops in my patients. }\end{array}$ & 2.9 & 72.5 & 4 & 1.2 \\
\hline $\begin{array}{l}+\quad \text { I have an important task in pres- } \\
\text { sure ulcer prevention. }\end{array}$ & 3.2 & 80 & 4 & 1.1 \\
\hline F5. Confidence in the effectiveness of & 6.9 & 86.3 & 8 & 1.2 \\
\hline $\begin{array}{l}+ \text { Pressure ulcers are preventable in } \\
\text { high risk patients. }\end{array}$ & 3.3 & 82.5 & 4 & 2.1 \\
\hline $\begin{array}{l}\text { - Pressure ulcers are almost never } \\
\text { preventable. }\end{array}$ & 3.6 & 90 & 4 & 2.4 \\
\hline Total scores & 39.9 & 76.7 & 52 & 3.8 \\
\hline
\end{tabular}

$\mathrm{F}=$ factor, $\mathrm{MS}=$ maximum score, $\mathrm{SD}=$ standard deviation, $-=$ negatively written, $+=$ positively written

In $4^{\text {th }}$ theme: "Responsibility in PI prevention" (mean=6.1, $\mathrm{SD}=0.9,76.3 \%$ ), the minimum mean score in this theme: "I am not responsible if a PI develops in my patients" (mean=2.9, $\mathrm{SD}=1.2,72.5 \%)$. And finally the $5^{\text {th }}$ theme: "Confidence in the effectiveness of prevention" (mean=6.9, $\mathrm{SD}=1.2,86.3 \%$ ), the maximum mean score in this theme: "PI is almost never preventable" (mean=3.6, $\mathrm{SD}=2.4,90 \%)$.

To evaluate the effect of demographic characteristics on nurses' attitudes, various statistical tests were performed. The only significant variable was 'years of employment in critical care units'; a Kruskal-Wallis test was used to test the statistically-significant difference between 3 groups $(0-5,6-10,>11)(\mathrm{p}=0.001)$.

The following variables also had no effect on the nurses' attitudes:

- Academic level $(\chi 2$ test, $\mathrm{p}=0.52)$

- $\quad$ Age group $\left(\chi^{2}\right.$ test, $\left.\mathrm{p}=0.32\right)$

- Whether they received training on PI (Mann-Whitney U, $\mathrm{p}=0.59)$

- Reading research articles about PI prevention (MannWhitney $\mathrm{U}, \mathrm{p}=0.380$ ).

\subsection{Perceived barriers}

Using a Likert scale (Table 4) participants were asked to identify their opinions about possible barriers faced by CCNs during clinical practice. Shortage of staff $(n=242,89.4 \%)$ was the most commonly cited barrier, followed by: ii) Lack of use of the risk assessment scale to prioritize severely ill patients $(n=229,84.8 \%)$, iii) Lack of satisfaction with nursing leadership ( $\mathrm{n}=228,84.4 \%)$, iv) Stressful working situation $(n=226,83.7 \%)$. 
Table 4. Perceived barriers to PU prevention

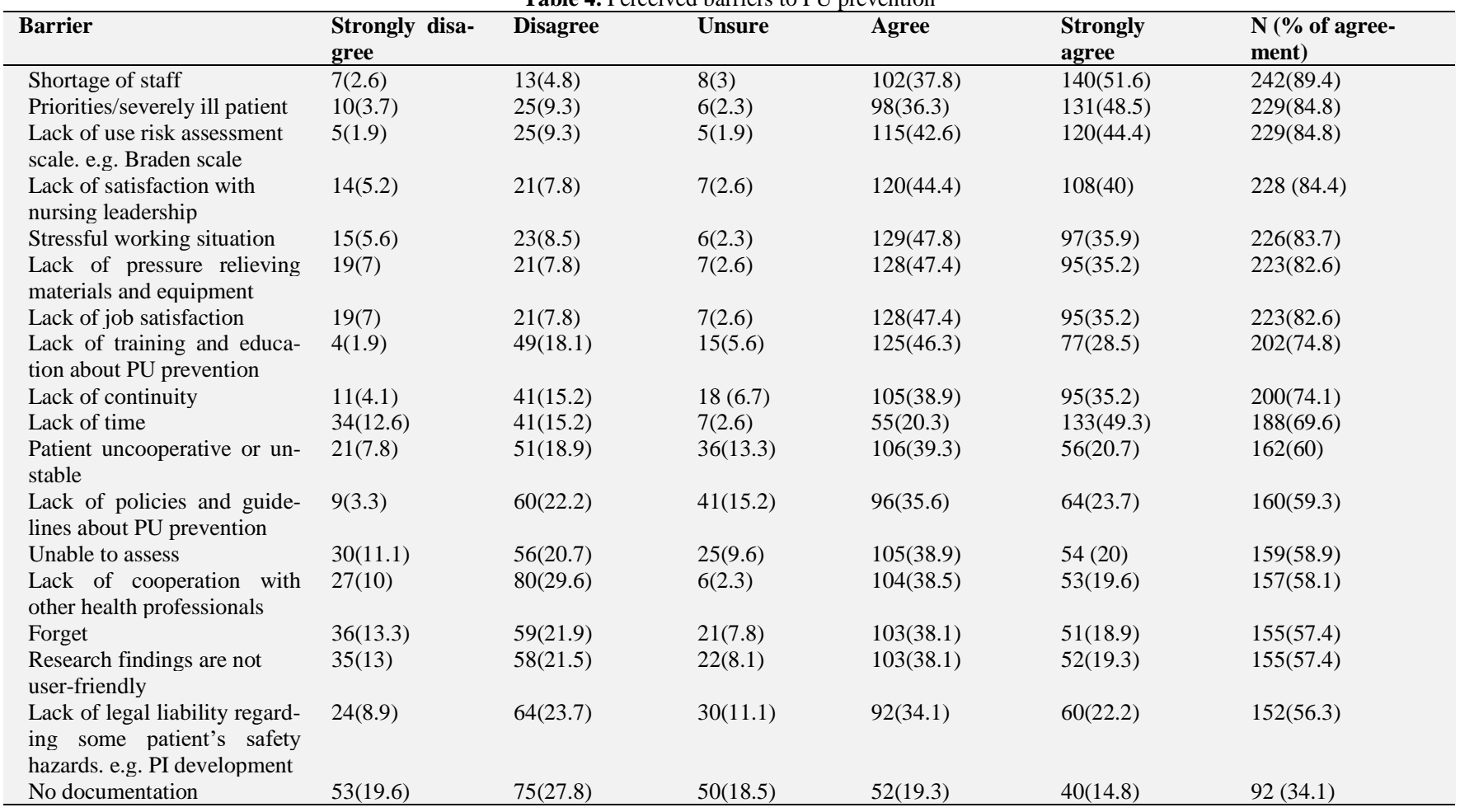

The barriers perceived to be the least important were: a) research findings are not user-friendly and are easily forgotten $(\mathrm{n}=155$, $57.4 \%)$, b) lack of legal liability $(\mathrm{n}=152,56.3 \%)$ and $\mathrm{c})$ no documentation $(\mathrm{n}=92,34.1 \%)$.

\section{Discussion}

Prevention of PI is considered one of the most significant indicators of the quality of patient care. Nursing interventions have a significant impact on PI avoidance and development. Therefore, PI constitutes a significant nurse-sensitive issue (Dilie \& Mengistu, 2015). This current research sought to gain an understanding of knowledge, attitudes and perceived barriers among CCNs in Jordan regarding PI prevention.

Sufficient knowledge and positive attitudes toward PI prevention is an essential factor to guide $\mathrm{CCNs}$, thereby enabling correct use of sufficient preventive actions to high-risk patients, as well as decreasing incidence rates of PI, duration of hospital stays, morbidity and mortality, and reducing the financial expenses of the patients and/or their families.

\subsection{Knowledge}

The overall mean knowledge score was $54.9 \%$, which is insufficient. Nurses working in specialized critical care units are expected to be knowledgeable and skillful; therefore this level was below what was expected. In comparison with earlier studies, participants showed relatively low mean knowledge scores (Usher et al., 2018; Simonetti Comparcini, Flacco, Di Giovanni, \&Cicolini, 2015; Nuru, Zewdu, Amsalu, \&Mehretie, 2015; Qaddumi\& Khawaldeh, 2014)

These results can be explained by there being inadequate knowledge regarding PI prevention in the college curriculum, which means that when the CCNs are still students, they may not be properly equipped for their tasks in the prevention of PI occurrence, and could be ill-prepared to nursing board exams like NCLEX in Jordan, before starting work in clinical fields. Furthermore, there are no incentives for Jordanian nurses to continue their training and education about PI prevention, or renew their reading of research articles. Furthermore, a lack of educational chances, influenced by such issues as the timing, accessibility, and expense of training, may be responsible for the low mean knowledge score recorded in this research.

By analyzing nurses' knowledge regarding the prevention of pressure injuries, we found that: a) level of education, b) 0-5 year employed in critical care units compared with $>11$ years, c) the training received on PI prevention and d) reading papers on PI prevention were all found to have a significant and independent effect on nurses' knowledge regarding the prevention of pressure injuries. These findings are in line with other studies (Källman \& Suserud, 2009; Ilesanmi, Ofi, \&Adejumo, 2012)

These results could be anticipated, given that the number of years employed in critical care units increases the nurses' levels of practice and knowledge. Actually, the benefit of years of employment is well identified as an important indicator of professional competence. The explanation could be years employed in the critical care unit provide a nurse with more opportunities to work with several specialists so that they can understand and learn from the professional expertise on display. Furthermore, longer serving nurses i) have more prolonged contact with patient care and ii) have better opportunities to apply new ways to prevent PI development, informed by their own mistakes in comparison to other nurses with fewer years of such experience.

Furthermore, encouraging nurses to read the latest publications about PI prevention is considered as an important strategy to raise nurse's knowledge regarding the issue of PI. (Simonetti et al., 2015; Tawalbeh et al., 2015). Finally, receiving training on PI prevention improves the opportunity for the nurses to obtain updated information and facts about PI related preventions.

\subsection{Attitudes}

The Jordanian CCNs obtained positive mean attitude scores (mean=39.9, $\mathrm{SD}=3.8,76.2 \%$ ). Positive mean attitude scores of participants concerning PI is essential in preventing or treating PI as when the attitude toward prevention becomes more positive, adequate preventive care will be given to more patients. The result 
is consistent with a Turkish study conducted by Ünver, Fındık, Özkan, \&Sürücü. (2017) and Dilie and Mengistu (2015).

According to the Theory of Planned Behaviour (TPB) (Ajzen, 2011), individual action is affected by the person's attitude towards the behavior. This attitude stems from beliefs that a particular behavior contributes to a particular effect; for example, PI prevention results in a decrease of PI development. The majority of participants in this current research felt that PI prevention should be a priority. Comparing to majority disagree that PI prevention is not that important.

The only significant finding from the demographic variables was 'years employed in a critical care unit'; the results being similar to those of Tubaishat et al. (2013). The CCNs who received training on PI prevention did not present higher attitude scores than the nurses who had not received such training. This finding is in line with other studies. (Beeckman et al., 2011; El Enein\& Zaghloul, 2011).

Throughout a crowded curriculum, it is very important to give nursing students appropriate material regarding practical knowledge and positive attitude to PI prevention and treatment strategies.

Improvement can be achieved by the adoption of new learning modes such as e-learning and simulation, to complement the more traditional teaching methods.

The biggest concern about attitudes toward PI prevention is a nurse's personal competency. This variable had the smallest scores, a result which was in line with the findings by Simonetti et al. (2015).

\subsection{Perceived barriers}

As stated earlier, there is a lack of research in Jordan concerning the perceived barriers to PI prevention in critical care units. Within this study, the most frequently documented barriers were: i) a shortage of staff, ii) priorities for dealing with severely ill patients, iii) lack of use of the risk assessment scale, and iv) lack of satisfaction with nursing leadership. Similar barriers were reported by other studies (Kallman\& Suserud, 2009; Tubaishat et al., 2011). A shortage of staff was the most commonly reported perceived barrier to PI prevention. The study's results can be explained by a shortage of nursing staff decreasing the time available to practice client health care. Insufficient patient-to-nurse ratios might restrict the delivery of high-quality care relevant to PI prevention.

Some preventive techniques, like changing the patient's position, are difficult to achieve without having support from other staff. Eventually, problems such as this may lead nurses not to prioritize PI prevention

In the current study, the majority of the participants failed to use a risk assessment scale. Sardo et al., (2015) reported similar results to the ones obtained in this current study. This finding can be explained by some nurses' thinking that their clinical evaluation is preferable to the use of a risk assessment scale and that the use of the risk assessment scale is time-consuming. Nurses who suffer from a lack of satisfaction with the nursing managers was considered as a major barrier to PI prevention

This finding may be explained by participants who are satisfied with the nursing managers are happy in their workplace, because they are encouraged to draw on their experiences and knowledge of techniques relevant to the prevention of PI.

Lack of pressure relieving materials and equipment in the workplace, with which to treat the injuries, was considered as the main barrier to PI prevention. This lack could be as a result of the fact that restricted use of sufficient equipment and pressure relieving materials may restrict the CCNs' ability and motivation to prevent PI development.

In Jordan, all patients were placed on standard mattresses; however, patients who were recognized to be at risk of developing PI were placed on a 'Dynamic' air mattress overlay.
Jordanian CCNs' do not employ new devices for PI prevention, such as i) low-pressure mattresses, ii) special foam mattresses, iii) pressure-redistributing mattresses, iv) profiling beds or v) heel and elbow protectors. The non-use of new devices might be influenced by the current challenging financial situation in Jordan, which is mirrored in the healthcare services. These research results are in line with those from Tubaishat et al. (2011), which identified that it was only the minority of Jordanian patients susceptible to PI who obtained adequate prevention measures and complementary equipment during their hospitalization.

\subsection{Limitations and strengths}

There are a variety of restrictions in this study that should be regarded. The application of a self-report questionnaire is considered as the main limitation of this study; data are collected only once, restricting the capability to draw accurate conclusions about any possible causality or association. Another restriction relates to the use of a convenience sample. Furthermore, information about unresponsive was not gathered. It is possible that nurses who declined to participate might be different from those who took part. This issue might restrict the generalizability of the results.

The inclusion of ten hospitals in Jordan in this study and the adequate sample size reinforce the generalizability and representativeness of the results and are considered as strong points of this study, thus decreasing any potential information bias. Also worth noting is the use of two new valid and reliable instruments used to collect data. i) the Pressure Ulcer Knowledge Assessment Tool (PUKAT) 2.0, and ii) Attitude Toward Pressure Ulcer Prevention (APuP).

\section{Conclusion}

In the current study, Jordanian CCNs positive mean attitude scores reveal well-adjusted behaviors. However, insufficient medical knowledge indicates only partial potential adherence to clinical guidelines for the prevention of PI, with negative consequences for the quality of the care being provided to patients.

It is suggested that efficient clinical education and learning programs be designed at hospitals or that CCNs should attend training programs to enable them to enhance the standards of their PI care. It is recommended that the PI prevention content in all nursing curricula should be reviewed and updated where appropriate.

The positive attitude scores registered by the Jordanian CCNs could represent a starting point for improving PI prevention practices.

Nevertheless, this positive attitude might be affected by current barriers such as a) shortage of staff, b) lack of use of any risk assessment scale in order to prioritize the care given to severely ill patients and) stressful working situations involving a lack of pressure relieving materials and equipment.

\section{What is already known about the topic?}

- Even with the use of evidence-based practice to prevent pressure injuries (PIs), it occurs in critically ill patients; the incident rates range between $14 \%$ to $51 \%$ of all hospitalized patients. In Jordan, a rate of $12 \%$ has been reported.

- Critical care nurses (CCNs), as frontline caregivers, bear much of the responsibility for the implementation of strategies to prevent PIs.

- To enhance the high quality of their caring, nurses should have up-to-date knowledge and practice regarding the prevention of pressure injuries.

\section{What this paper adds}

- Jordanian CCNs positive mean attitude scores reveal well-adjusted behaviors. 
- It is recommended that the pressure injuries prevention content in all nursing curricula should be reviewed and updated where appropriate.

- The positive attitude scores registered by the Jordanian CCNs could represent a starting point for improving pressure injuries prevention practices.

- A positive attitude might be affected by current barriers such as a) shortage of staff, b) lack of use of any risk assessment scale in order to prioritize the care given to severely ill patients and c) stressful working situations involving a lack of pressure relieving materials and equipment.

\section{Acknowledgments}

The author is grateful for all CCNs who participate in this study

\section{Competing interests}

The authors declare that they have no competing interests.

\section{References}

[1] Ajzen I, Gilbert Cote N. Attitudes and the prediction of behavior (2008). In: Crano WD, Prislin R, editors. Attitudes and attitude change. New York: Psychology Press; p. 289-311.

[2] Ajzen, I. (2011). The theory of planned behaviour: reactions an reflections.Psychology \& Health, 26(9), 1113-1127.DOI: http://dx.doi.org/10.1080/08870446.2011.613995

[3] Bashayreh, I., Saifan, A., Batiha, A. M., \& Abu Ruz, M. (2013). Family Presence during CPR in Adult Critical Care Settings: Hearing the Voice of Jordanian Health Professionals. Life Science Journal, 10(4), 1738-1748.

[4] Bashayreh, I., Saifan, A., Batiha, A. M., Timmons, S., \& Nairn, S. (2015). Health professionals' perceptions regarding family witnessed resuscitation in adult critical care settings. Journal of clinical nursing, 24(17-18) http://dx.doi.org/10.1111/jocn.12875.

[5] Batiha, A. M. (2014). Pain management barriers in critical care units: A qualitative study. International Journal of Advanced Nursing Studies, 3(1), 1. http://dx.doi.org/10.14419/ijans.v3i1.1494.

[6] Beeckman, D., Defloor, T. Demarré, L., Van Hecke, A., \& Vanderwee, K. (2010). Pressure ulcers: Development and psychometric evaluation of the Attitude towards Pressure ulcer Prevention instrument (APuP). International Journal Of Nursing Studies, 47(11), 1432-1441. doi:10.1016/j.ijnurstu.2010.04.004

[7] Beeckman, D., Defloor, T., Schoonhoven, L., \& Vanderwee, K. (2011). Knowledge and attitudes of nurses on pressure ulcer prevention: a cross-sectional multicenter study in Belgian hospitals. Worldviews On Evidence-Based Nursing, 8(3), 166-176. doi:10.1111/j.1741-6787.2011.00217.x

[8] Beeckman, D., Vanderwee, K., Demarré, L., Paquay, L., Van Hecke, A., \& Defloor, T. (2010). Pressure ulcer prevention: development and psychometric validation of a knowledge assessment instrument. International Journal Of Nursing Studies, 47(4), 399-410. doi:10.1016/j.ijnurstu.2009.08.010

[9] Cox, J. , Schallorm, M., 2017. Pressure Injuries in Critical Care: A Survey of Critical Care Nurses. Critical Care Nurse, 37(5), 46-56. doi:10.4037/cen2017928

[10] Dilie, A., \& Mengistu, D. (2015). Assessment of Nurses' Knowledge, Attitude, and Perceived Barriers to Expressed Pressure Ulcer Prevention Practice in Addis Ababa Government Hospitals, Addis Ababa, Ethiopia, 2015. Advances In Nursing, 2015(1), doi:10.1111/j.1471-6712.2008.00627.x

[11] El Enein, N. A., \& Zaghloul, A. A. (2011). Nurses' knowledge of prevention and management of pressure ulcer at a health insurance hospital in Alexandria. International Journal Of Nursing Practice, 17(3), 262-268. doi:10.1111/j.1440-172X.2011.01933.x

[12] Galvão, N. S., Serique, M. A. B., Santos, V. L. C. D. G., \&Nogueira, P. C.(2017). Knowledge of the nursing team on pressure ulcer prevention. RevistaBrasileira De Enfermagem, 70(2), 294-300. doi:10.1590/0034-7167-2016-0063
[13] Ilesanmi, R. E., Ofi, B. A., \& Adejumo, P. O. (2012). Nurses' knowledge of pressure ulcer prevention in ogun state, Nigeria: results of a pilot survey . Ostomy/Wound Management, 58(2), 24-32.

[14] Källman, U., \& Suserud, B. (2009). Knowledge, attitudes and practice among nursing staff concerning pressure ulcer prevention and treatment--a survey in a Swedish healthcare setting. Scandinavian Journal Of Caring Sciences, 23(2), 334-341.

[15] Manderlier, B., Van Damme, N., Vanderwee, K., Verhaeghe, S. Van Hecke, A., \& Beeckman, D. (2017). Development and psychometric validation of PUKAT2 $\bullet 0$, a knowledge assessment tool for pressure ulcer prevention. International Wound Journal, 14(6), 1041-1051.doi:10.1111/iwj.12758

[16] Nuru, N., Zewdu, F., Amsalu, S., \& Mehretie, Y. ,2015. Knowledge and practice of nurses towards prevention of pressure ulcer and associated factors in Gondar University Hospital, Northwest Ethiopia. BMC Nursing, 14(1), 1-8. doi:10.1186/s12912-015-0076-8

[17] Obead, K. A., Batiha, A. M., Al-Jauissy, M. S., Alhalaiqa, F., \& AlBashtawy, M. (2014). Impact of radiotherapy treatment on Jordanian cancer patients' quality of life and fatigue. International Journal of Advanced Nursing Studies, 3(1), 6-12. http://dx.doi.org/10.14419/ijans.v3i1.798

[18] Ozyurek, P., \& Yavuz, M. (2015). Prevention of pressure ulcers in the intensive care unit: a randomized trial of 2 viscoelastic foam support surfaces. Clinical Nurse Specialist, 29(4), 210-217. doi:10.1097/NUR.0000000000000136

[19] Qaddumi, J., \& Khawaldeh, A. (2014). Pressure ulcer prevention knowledge among Jordanian nurses: a cross- sectional study. BMC Nursing, 13(1), 6. doi:10.1186/1472-6955-13-6

[20] Qaseem, A., Humphrey, L. L., Forciea, M. A., Starkey, M., \&Denberg, T. D. (2015). Treatment of Pressure Ulcers: A Clinical Practice Guideline From the American College of Physicians. Annals Of Internal Medicine, 162(5), 370-379. doi:10.7326/M14-1568

[21] Sardo, P., Simões, C., Alvarelhão, J., Costa, C., Simões, C. J., Figueira, J., \& ... Melo, E. (2015). Pressure ulcer risk assessment: retrospective analysis of Braden Scale scores in Portuguese hospitalised adult patients. Journal Of Clinical Nursing, 24(21/22), 3165-3176. doi:10.1111/jocn.12927

[22] Schlüer, A. (2017). Pressure ulcers in maturing skin - A clinical perspective. Journal Of Tissue Viability, 26(1), 25.doi:10.1016/j.jtv.2016.10.001

[23] Serpa, L. F., Santos, V. G., Oliveira, A. S., Caetano, V. C., \&Donadon, S. R. (2011). Incidence of pressure ulcers in critical care patients. RevistaEstima, 9(3), 21-26.

[24] Simonetti, V., Comparcini, D., Flacco, M. E., Di Giovanni, P., \&Cicolini, G. , 2015. Nursing students' knowledge and attitude on pressure ulcer prevention evidence-based guidelines: A multicenter cross-sectional study. Nurse Education Today, 35(4), 573579.doi:10.1016/j.nedt.2014.12.020

[25] Strand, T., \& Lindgren, M. (2010). Knowledge, attitudes and barriers towards prevention of pressure ulcers in intensive care units: A descriptive cross-sectional study. Intensive And Critical Care Nursing, 26(6), 335-342. doi:10.1016/j.iccn.2010.08.006

[26] Tawalbeh, L. I., Tubaishat, A., Batiha, A.M., Al-Azzam, M., \& AlBashtawy, M. (2015). The relationship between social support and adherence to healthy lifestyle among patients with coronary artery disease in the north of Jordan. Clinical Nursing Research, 24(2), 121-138. http://dx.doi.org/10.1177/1054773813501194.

[27] Tubaishat, A., Aljezawi, M., \& Al Qadire, M. 2013. Nurses' attitudes and perceived barriers to pressure ulcer prevention in Jordan. Journal Of Wound Care, 22(9), 490497.doi:10.12968/jowc.2013.22.9.490

[28] Tubaishat, A., Anthony, D., \& Saleh, M. (2011). Pressure ulcers in Jordan: a point prevalence study. Journal Of Tissue Viability, 20(1), 14-19. doi:10.1016/j.jtv.2010.08.001

[29] Ünver, S., Fındık, Ü. Y., Özkan, Z. K., \&Sürücü, Ç. (2017). Attitudes of surgical nurses towards pressure ulcer prevention. Journal Of Tissue Viability, 26(4), 277-281. doi:10.1016/j.jtv.2017.09.001

[30] Usher, K., Woods, C., Brown, J., Power, T., Lea, J., Hutchinson, M., \& ... Jackson, D. (2018). Australian nursing students' knowledge and attitudes towards pressure injury prevention: A cross-sectional study. International Journal of Nursing Studies, 8114-20. doi:10.1016/j.ijnurstu.2018.01.015

[31] Yamada, H., Inoue, Y., Shimokawa, Y., \& Sakata, K. (2017). Skin stiffness determined from occlusion of a horizontally running microvessel in response to skin surface pressure: a finite element study of sacral pressure ulcers. Medical \& Biological Engineering \& Computing, 55(1), 79-88. doi:10.1007/s11517-016-1500-2 